\title{
p63 and the epithelial stem cell: more than status quo?
}

\author{
Frank McKeon ${ }^{1}$ \\ Department of Cell Biology, Harvard Medical School, Boston, Massachusetts 02115, USA
}

The discovery of p63, the most ancient member of the p53 family (for review, see Yang et al. 2002), was soon followed by back-to-back reports of a remarkable phenotype of mice lacking this gene: They die perinatally due to the absence of a large number of epithelial structures including skin, breast, prostate, and urothelia, among others (Mills et al. 1999; Yang et al. 1999). Despite the contemporaneous nature of these publications, they expressed profound disagreement regarding the function of p63, as reflected in the mouse mutants. Mills et al. (1999) argued that p63 was essential for the commitment of a simple ectoderm to epidermal lineages, whereas Yang et al. (1999) argued that commitment and differentiation of the ectoderm were essentially intact in these mice, and that what was defective was the "proliferative potential" of the epithelial stem cells (Fig. 1). Principals from the first group have now addressed this problem from fundamentally different angles and have proposed new and unexpected functions of the p63 gene in epithelial commitment, maintenance, and differentiation (Koster et al. 2004).

\section{p63 and epithelial morphogenesis-marker of progenitor cells?}

Recent work by Koster et al. (2004) addresses the relationship between p63 and epithelial morphogenesis, and, by extension, the interface of stem cell biology and the origins of some of the most common forms of human cancers. Although the precise functional relationship between p63 and its illustrious cousin p53 in tumorigenesis remains the center of another debate (Yang et al. 2002; Melino et al. 2003), antibodies to p63 revealed in stark detail something not seen with p53-very high levels of expression in the basal or progenitor cells of many of the tissues that sustain a majority of cancers and other neoplasias including skin, esophagus, and urothelia, as well as secretory epithelial tissues including lacrymal

${ }^{1}$ Correspondence.

EMAIL fmckeon@hms.harvard.edu; FAX (617) 432-6655.

Article and publication are at http://www.genesdev.org/cgi/doi/10.1101/ gad.1190504. glands, mammary glands, and prostate glands (Yang et al. 1998). The standout epithelial tissues lacking p63 in progenitor layers are the small and large intestine. Although it is clear that p63 expression is not limited to "stem" cells of the epithelial tissues that express this gene, a number of studies contend that the stem cells in fact express the highest levels of p63 (Pellegrini et al. 2001). That p63 is among the best markers of epithelial progenitor cells provokes the obvious question regarding its local function. Notably, the undifferentiated ectoderm in the mouse that gives rise to cells of the stratified epidermis at embryonic day 14 (E14) expresses high levels of p63 as early as E8.5, far in advance of any obvious decision towards commitment (Fig. 2). Thus signals from underlying mesoderm appear necessary to trigger discrete functions of p63 in the ectoderm toward commitment, differentiation, and regeneration (Morgan et al. 1998; St. Jacques et al. 1998).

Complicating any prediction of the function of p63 was the observation that this gene is immensely more complex than the more recently evolved p53 gene, which itself only gives rise to a single transcript and single transcriptional activator polypeptide (Yang et al. 1998, 2002). In fact, the p63 gene has at least two major promoters (termed TA and $\Delta \mathrm{N}$ ) that drive a minimum of three transcripts encoding transactivating (TA) and nominally nontransactivating $(\Delta \mathrm{N})$ isoforms (Fig. 3). There is general agreement that the progenitor cell layers of skin, breast, and prostate express high levels of the nontransactivating $\Delta \mathrm{Np} 63$ isoforms to the near exclusion of the transactivating isoforms (Yang et al. 1998, 1999; Liefer et al. 2000; Signoretti et al. 2000; Pelligrini et al. 2001; DiRenzo et al. 2002; Nylander et al. 2002; Westfall et al. 2003). The paucity of TAp63 isoforms suggested that $\Delta \mathrm{Np} 63$ must be shouldering much of the function of p63 in epithelial progenitor cells. Although good evidence exists that $\Delta \mathrm{Np} 63 \mathrm{can}$, in fact, engage in transcriptional activation processes (Duijf et al. 2002), it has generally been assumed that $\Delta \mathrm{Np} 63$ is a repressor molecule against TAp63 and p53, or simply functions to silence a set of genes in order to establish the correct genetic environment in epithelial progenitor cells. The work by Koster et al. (2004) offers fundmentally new definitions of the roles of the p63 isoforms in epithelial morphogenesis. 
Figure 1. Deduction of p63 function in epithelial morphogenesis. Schematic of epithelial morphogenesis in tissues expressing high levels of p63 in progenitor cell layers, including skin, breast, prostate, and urothelia. The steps where the process of epidermal development is blocked in p63-null mice were deduced separately by Mills et al. (1999) and Yang et al. (1999) as commitment and proliferative potential of stem cells, respectively.

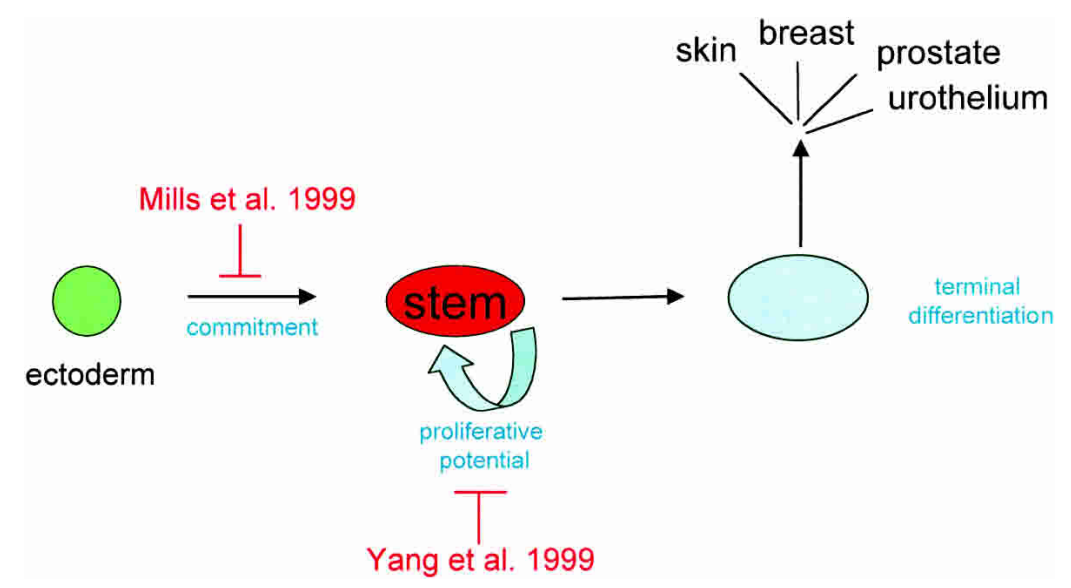

\section{Houston, we have a problem: epithelial catastrophe in the absence of p63}

Given the curiously high expression of $\Delta \mathrm{Np} 63$ in most regenerative epithelia, it was thought that a mouse knockout model would enlighten our notions of how this apparently dominant-negative transcription factor participates in tissue morphogenesis. Instead, the models created by Mills et al. (1999) and Yang et al. (1999) have generated a vexing degree of disagreement even after first glance. To begin with, both groups generated embryonic stem cells with disruptions in exons common to both the TA and $\Delta \mathrm{N}$ isoforms so that the resulting mice displayed the consequences of the combined loss of these apparently conflicting gene products (Mills et al. 1999; Yang et al. 1999). This lack of finesse aside, the resulting overall phenotypes observed by the two groups were identical: embryos that went to term but displayed only rudimentary limbs, no skin to speak of from any casual inspection, and profound defects or frank loss of the entire spectrum of epithelial tissues that normally express p63 at high levels in their progenitor layers. This unprecedented phenotype underscored the significance of p63 in epithelial morphogenesis, but demanded considerable forensic analysis to determine what went wrong. Given that the ectoderm appears indistinguishable in wild-type and p63-null mice, p63 had to be responsible for either commitment to an epidermal cell fate, epidermal differentiation, or "maintenance" of progenitor cells of this tissue (Fig. 1). Analysis of the skin was the common proving ground to distinguish among these possibilities because of the large surface area and ready availability of commitment and differentiation markers.

Despite this situation, the groups saw things very differently. Mills et al. (1999) saw no stratified epidermis nor the presence of differentiation markers such as loricrin or involucrin, and naturally concluded that p63 was required for commitment of the immature ectoderm to epidermal lineages. Meanwhile, Yang et al. (1999) saw clear evidence for a stratified, albeit tattered, epidermis in the p63-null embryos, and more importantly found that these remnants stained brightly with antibodies against differentiation markers including lorocrin, involucrin, and fillagrin. Yang et al. (1999) therefore concluded that p63 was not required for either commitment of the ectoderm to epidermal lineages or for the differentiation of committed cells into a stratified squamous epithelium. Given the intense staining by p63 antibodies of the progenitor cell layers, coupled with excluding functions in differentiation, Yang et al. (1999) reasoned that p63 was essential for the proliferative potential of the epidermal stem cells. They explained the residual clumps of differentiated epithelial cells on the surface of late-gestation mutant embryos as the consequence of mass differentiation and loss of the epidermal stem cells. Surprisingly, this apparent conflict in perception of p63 function has remained largely unaddressed until the recent publication by principals of the group that originally promulgated the link between p63 and commitment (Mills et al. 1999; Koster et al. 2004).

Figure 2. Expression of p63 in ectoderm versus stratified epidermis. Immunohistochemistry with the antip63 monoclonal antibody showing p63 expression in the undifferentiated single-layer ectoderm of an E10 embryo (left panel) compared with p63 expression in a 30-day-old epidermis (right panel) where p63 is highly expressed in the basal layer and generally lost with stratification (F. Pinto, C. Crum, F. McKeon, unpubl.).

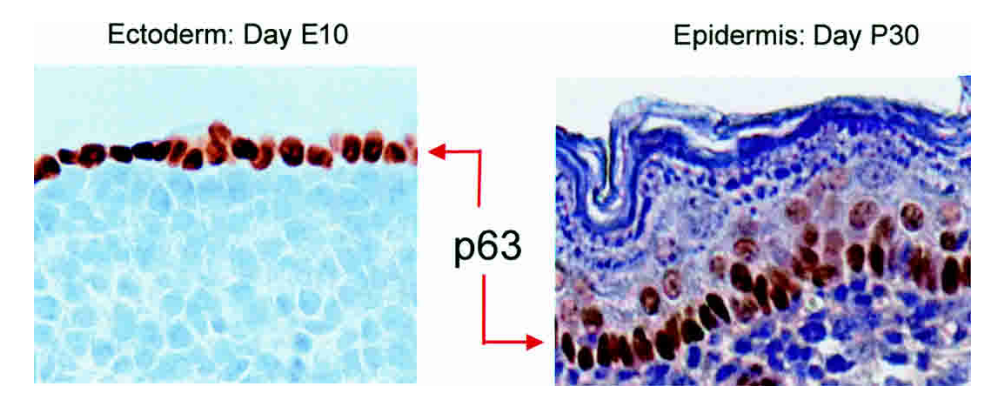




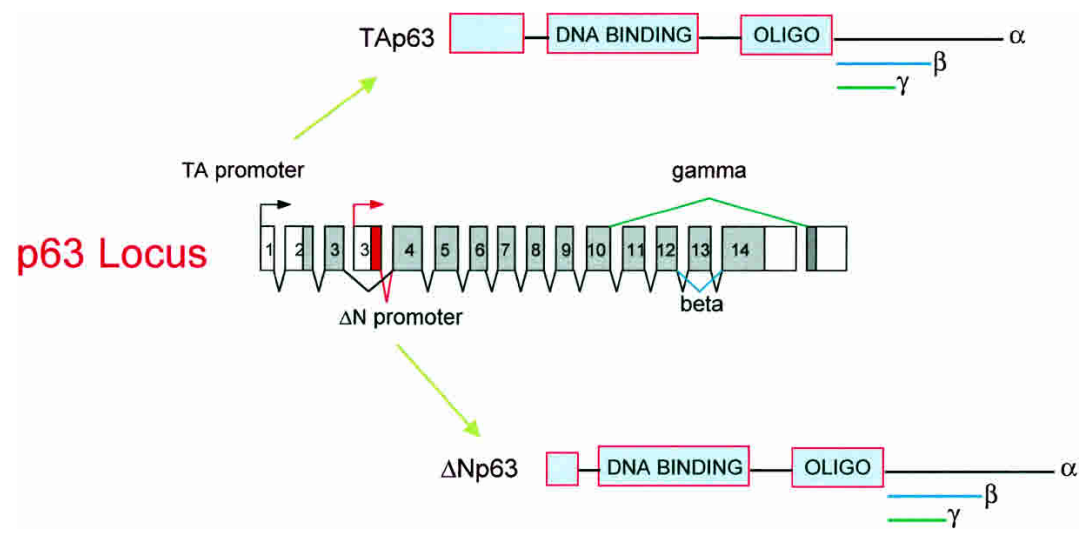

Figure 3. Generation of $\mathrm{TA}$ and $\Delta \mathrm{N}$ isoforms from the p63 gene. Schematic of the exon structure and promoter positions of the p63 gene as well as the splicing events that give rise to the TA and $\Delta \mathrm{N}$ isoforms and their respective $\beta$ and $\gamma$ spicing variants. The TA isoforms have an acidic $\mathrm{N}$-terminal domain common to many transcriptional activators whereas the $\Delta \mathrm{N}$ isoforms lack this acidic N-terminal domain. The p63 gene is distributed over $\sim 200 \mathrm{~kb}$ of mouse chromosome 16 and human chromosome 3q27.

\section{Ectoderm lacking p63 never stacks up}

Rather than the clumps of differentiated epithelial remnants described by Yang et al. (1999), Koster et al. (2004) observed that the p63-null embryos were draped by a layer of simple, undifferentiated epithelial cells expressing K18, a marker of all simple epithelia, including, significantly, the ectoderm prior to stratification. Although the origin of these simple epithelial cells was not tracked from the primitive ectoderm to the late-stage embryos, their presence certainly supports the conclusion rendered that these are the end products of a simple ectoderm that failed to commit to a stratified epithelial lineage. It was, in fact, the presence of these simple epithelial cells on the surface of the p63 mutant that led Koster et al. (2004) to surmise that in the absence of p63, the surface ectoderm cannot commit to a stratifying squamous epithelium and instead propagates on the dermis as a single-layered, simple epithelium. There was some sense that these undifferentiated cells would be ideal for testing what features of p63 were required to move them beyond their apparently uncommitted state. Before doing this, however, Koster et al. (2004) used PCR reactions to determine the presence and kinetics of p63 expression during development. Surprisingly, this PCR analysis of whole embryos indicated that TAp63 isoforms, and not $\Delta \mathrm{Np} 63$ isoforms, dominated the expression profile from E7.5 through E15, which encompasses the entire interval during which the ectoderm commits to epidermal lineages and completes initial stratification programs. It would follow then that the high expression of p63 observed in the prestratification ectoderm by immunofluorescence would have to be predominantly the TAp63 isoform. Thus the ectoderm would have to express p63 isoforms with a completely different bias observed for the immature epithelial cells of breast, prostate, or skin. Although the degree of normalization of these PCR reactions was unclear, and the substrate RNAs were derived from whole embryos rather than epithelial tissues, Koster et al. (2004) felt the most likely conclusion was that the TAp63 isoforms functioned to drive commitment of the ectoderm to epidermal lineages. Whereas other experiments have hinted at a role for p63 in directing differentiation programs of keratinocytes (De
Laurenzi et al. 2000), the findings by Koster et al. (2004) could not have been predicted from present knowledge.

\section{TAp63 isoforms: keratinocyte commitment factors?}

If this rather heretical view was correct, Koster et al. (2004) reasoned that TAp63 isoforms could have a determining effect on otherwise uncommitted epithelial cells, not unlike the effects of MyoD, one of a family of bHLH proteins involved in driving muscle differentiation, on 10T1/2 cells (Weintraub et al. 1991). Although the simple epithelia from the surface of p63-null embryos proved too fragile for such complementation experiments, a wide range of cells, including rat kangaroo Ptk2 cells, HR9 mouse parietal endodermal cells, and F9 embryonal carcinoma cells, showed strong keratin 5 and 14 expression upon exogenous TAp63 expression, whereas $\Delta \mathrm{Np} 63$ expression induced neither of these keratinocyte markers. These tissue culture results emboldened Koster et al. to test p63 isoform expression in conditional transgenic models specific to epithelial cells lining the bronchioles of the lung-which otherwise express neither p63 nor stratified epithelial markers. Here the results were also dramatic: TAp63 and $\Delta$ Np63 were seen to be expressed in the target type II alveolar cells, but only those mice expressing TAp63 developed rather severe squamous metaplasia expressing K5 and K14, early markers of squamous differentiation. Given that squamous metaplasia is a reactive condition in the lung to various insults, it would have been reassuring to see that the squamous metaplasia expressed the exogenous, tagged TAp63. However, Koster et al. (2004) were also able to repeat these experiments in a simpler system of driving TAp63 in basal cells of the skin and hair follicles using conditional promoters. Interestingly, these mice also showed extensive hyperplasia of keratinocytes marked by the presence of immature markers high up in stratified layers-an indication that the differentiation program was slowed or largely impaired in cells overexpressing TAp63. Collateral experiments driving TAp63 expression in vivo and in vitro in keratinocytes shored up the notion that TAp63 overexpression blocks squamous differentiation programs while simultaneously 
Figure 4. Assignment of p63 isoform functions in epithelial morphogenesis. Schematic of epithelial morphogenesis depicting the roles ascribed to TAp63 and $\triangle \mathrm{Np63}$ isoforms (Koster et al. 2004). In particular, TAp63 is seen to both promote commitment of the ectoderm to epithelial lineages and to suppress the differentiation of such committed progenitor cells. $\Delta \mathrm{Np} 63$, on the other hand, acts to promote terminal differentiation via its competition and suppression of TAp63 actions in these cells.

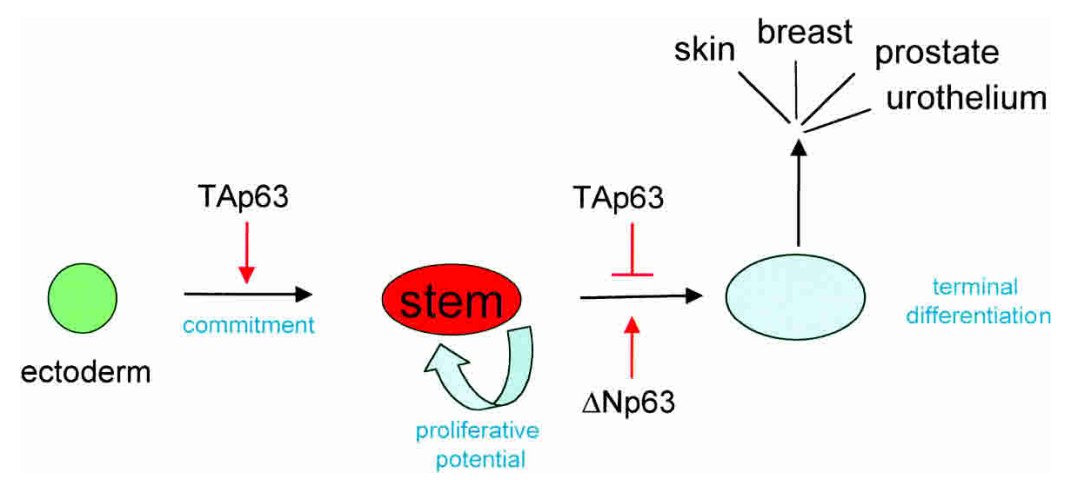

triggering the overall process of commitment. One elaboration, then, for the peculiar role of TAp63 is that it both directs commitment and then retains the committed cell in the immature state marked by high proliferative potential with a limited tendency to differentiate. Given this, Koster et al. (2004) float the startling concept that the $\Delta$ Np63 isoforms function to neutralize TAp63 to permit differentiation (Fig. 4). How this happens was not addressed, but it presumably involves $\Delta$ Np63's dominant-negative activity towards TAp63 (Yang et al. 1998). The recasting of $\Delta \mathrm{Np} 63$ as a differentiation factor rather than an immaturity or stem cell maintenance factor represents the final contradiction with the concepts of p63 function put forth by Yang et al. $(1999,2002)$.

\section{What is to be done?}

The findings by Koster et al. (2004) open entirely new vistas into the social fabric of p63 expression products and how the two apparently conflicting sets of p63 isoforms derived from this gene cooperate to effect epithelial morphogenesis. The strengths of this work include the demonstration that TAp63 can drive at least some markers of keratinocyte genetic programs in disparate cells and that the consequences of conditional expression of TAp63 in transgenic mice are consistent with this deterministic function of TAp63. Additionally, strong evidence is presented for the unexpected effect of TAp63 as an inhibitor of keratinocyte differentiation. What remains enigmatic about these results is the previous observations that $\Delta \mathrm{Np} 63$ is apparently the overwhelmingly dominant p63 isoform in the basal cells of many epithelial tissues-in fact, the only isoform detected in cultured immature epithelial cells using the standard anti-p63 monoclonal antibody. Such an overwhelming ratio of $\Delta \mathrm{N}$ to TAp63 might be required to dampen TAp63's activity, and these data do not explain the observation that $\Delta \mathrm{Np} 63$ is lost with keratinocyte differentiation rather than enhanced, as might be expected from the functions attributed to it by Koster et al. (2004). In fact, the only work to cite anti-TAp63 antibodies saw TAp63 expressed in suprabasal layers that generally lack $\Delta$ Np63 (Nylander et al. 2002). Like all interesting papers, this one inspires as many questions as it solves. These findings also underscore the need to examine the conse-

quences of isoform-specific knockouts within the p63 locus, a process that should be feasible given the large distance between the TA and $\Delta \mathrm{N}$ promoters. In view of the finding that TAp63 can drive keratinocyte commitment programs even in diverse cell types, it should be possible to describe the TAp63-dependent genetic program that might offer important insights into not only lineage commitment but also progenitor cell maintenance. Finally, it will be important to generate better isoform-specific reagents including antibodies and siRNA strategies to assess the dynamics of the TA/ $\mathrm{Np} 63$ ratios and how they dictate decisions regarding commitment, differentiation, and stem cell maintenance.

\section{Acknowledgments}

We thank Howard Green, Chris Crum, and members of the lab for helpful discussions.

\section{References}

De Laurenzi, V., Rossi, A., Terrinoni, A., Barcaroli, D., Levrero, M., Costanzo, A., Knight, R.A., Guerrieri, P., and Melino, G. 2000. p63 and p73 transactivate differentiation gene promoters in human keratinocytes. Biochem. Biophys. Res. Comm. 273: 342-346.

DiRenzo, J., Signoretti, S., Nakamura, N., Rivera-Gonzalez, R., Sellers, W., Loda, M., and Brown, M. 2002. Growth factor requirements and basal phenotype of an immortalized mammary epithelial cell line. Cancer Res. 62: 89-98.

Duijf, P.H., Vanmolkot, K.R., Propping, P., Friedl, W., Krieger, E., McKeon, F., Dotsch, V., Brunner, H.G., and van Bokhoven, H. 2002. Gain-of-function mutation in ADULT syndrome reveals the presence of a second transactivation domain in p63. Hum. Mol. Genet. 11: 799-804.

Liefer, K.M., Koster, M.I., Wang, X.J., Yang, A., McKeon, F., and Roop, D.R. 2000. Down-regulation of p63 is required for epidermal UV-B-induced apoptosis. Cancer Res. 60: 4016-4020.

Koster, M.I., Kim, S., Mills, A.A., DeMayo, F.J., and Roop, D.R. 2004. p63 is the molecular switch for initiation of an epithelial stratification program. Genes \& Dev. 18: 126-131.

Melino, G., Lu, X., Gasco, M., Crook, T., and Knight, R.A. 2003. Functional regulation of p73 and p63: Development and cancer. Trends Biochem. Sci. 28: 663-670.

Mills, A.A., Zheng, B., Wang, X.J., Vogel, H., Roop, D.R., and Bradley, A. 1999. p63 is a p53 homologue required for limb and epidermal morphogenesis. Nature 398: 708-713. 
Morgan, B.A., Orkin, R.W., Noramly, S., and Perez, A. 1998. Stage-specific effects of sonic hedgehog expression in the epidermis. Dev. Biol. 201: 1-12.

Nylander, K., Vojtesek, B., Nenutil, R., Lindgren, B., Roos, G., Zhanxiang, W., Sjostrom, B., Dahlqvist, A., and Coates, P.J. 2002. Differential expression of p63 isoforms in normal tissues and neoplastic cells. J. Pathol. 198: 417-427.

Pellegrini, G., Dellambra, E., Golisano, O., Martinelli, E., Fantozzi, I., Bondanza, S., Ponzin, D., McKeon, F., and De Luca, M. 2001. p63 identifies keratinocyte stem cells. Proc. Natl. Acad. Sci. 98: 3156-3161.

Signoretti, S., Waltregny, D., Dilks, J., Isaac, B., Lin, D., Garraway, L., Yang, A., Montironi, R., McKeon, F., and Loda, M. 2000. p63 is a prostate basal cell marker and is required for prostate development. Am. J. Pathol. 157: 1769-1775.

St-Jacques, B., Dassule, H.R., Karavanova, I., Botchkarev, V.A., Li, J., Danielian, P.S., McMahon, J.A., Lewis, P.M., Paus, R., and McMahon, A.P. 1998. Sonic hedgehog signaling is essential for hair development. Curr. Biol. 8: 1058-1068.

Weintraub, H., Davis, R., Tapscott, S., Thayer, M., Krause, M., Benezra, R., Blackwell, T.K., Turner, D., Rupp, R., Hollenberg, S., et al. 1991. The myoD gene family: Nodal point during specification of the muscle cell lineage. Science 251: 761-766.

Westfall, M.D., Mays, D.J., Sniezek, J.C., and Pietenpol, J.A. 2003. The $\delta \mathrm{Np} 63 \alpha$ phosphoprotein binds the p21 and 14-3-3 sigma promoters in vivo and has transcriptional repressor activity that is reduced by Hay-Wells syndrome-derived mutations. Mol. Cell Biol. 23: 2264-2276.

Yang, A., Kaghad, M., Wang, Y., Gillett, E., Fleming, M.D., Dotsch, V., Andrews, N.C., Caput, D., and McKeon, F. 1998. p63, a p53 homolog at 3q27-29, encodes multiple products with transactivating, death-inducing, and dominant-negative activities. Mol. Cell 2: 305-316.

Yang, A., Schweitzer, R., Sun, D., Kaghad, M., Walker, N., Bronson, R.T., Tabin, C., Sharpe, A., Caput, D., Crum, C., et al. 1999. p63 is essential for regenerative proliferation in limb, craniofacial and epithelial development. Nature 398: 714718.

Yang, A., Kaghad, M., Caput, D., and McKeon, F. 2002. On the shoulders of giants: p63, p73 and the rise of p53. Trends Genet. 18: 90-95. 


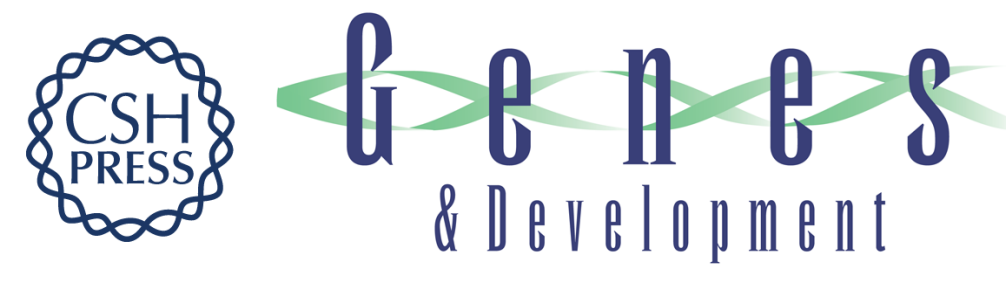

\section{p63 and the epithelial stem cell: more than status quo?}

\section{Frank McKeon}

Genes Dev. 2004, 18:

Access the most recent version at doi:10.1101/gad.1190504

References This article cites 17 articles, 6 of which can be accessed free at: http://genesdev.cshlp.org/content/18/5/465.full.html\#ref-list-1

License

Email Alerting Receive free email alerts when new articles cite this article - sign up in the box at the top Service right corner of the article or click here.

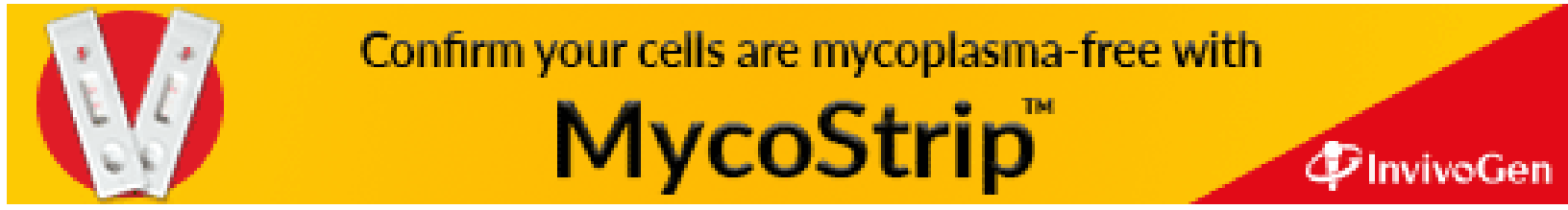

